The definitive, edited version of this article is published in:

Art Libraries Journal, 40, no. 4, pg. 4-7.

\title{
Open Access and the Future of Art Scholarship
}

\author{
Alexander Watkins
}

\begin{abstract}
7 here are many arguments for the necessity of open access, scholarship that 1 is freely available online; however, many of these arguments do not apply to art scholarship-is it then still necessary to change the publishing model? I argue that it is; the high price of access to traditional publications closes art scholarship to all but privileged Western academics. Open access is key to creating a globally integrated community of art scholars and reengaging the public in art discourse. Librarians can help facilitate a scholarship that is accessible to all.
\end{abstract}

\section{Introduction}

Open access scholarship is scholarship that is freely available online, without the paywalls that typify traditional e-publishing. The open access movement aims to eliminate all such barriers to accessing information. Open access is often associated with the sciences due to these disciplines' particularly high-priced journals, government funding and associated open access mandates, and public demand for scientific information, particularly in the context of health sciences. In the arts, open access is notably behind the curve, however this does not mean that it is not just as vital for the health of art scholarship. In fact, just the opposite: open access is key to creating relevant global art scholarship and reengaging the public in art discourse.

Since open access is so closely tied to the sciences many of the arguments for open access publishing do not align with the very different conditions of art scholarship. Open access is often presented as a solution to the skyrocketing price of journals. Indeed, the journal crisis has been the rallying cry of much of the open access movement, especially for libraries who foot the bill. But in the arts this is not the case; the average price for art journals is among the lowest of any discipline. ${ }^{1}$ If there is no journal crisis in the arts, why do we still need open access? The fact that many research papers receive funding from government agencies has been the impetus behind major open access mandates. But most of this funding flows to science research. If art scholarship isn't taxpayer funded, is there the same moral requirement that this research is shared with the public? Often medical and other scientific literature is cited as a vital public interest. People facing difficult medical decisions should have a right to read the most up-to-date medical scholarship. Science can improve people's lives. But the arts are different. We have no technological innovations nor medical breakthroughs. If many of the arguments for open access do not apply to art scholarship, do we still need to change the publishing model, and if so, how do we convince others of open access's importance?

We can add to these obstacles, the logistical challenges for open access in the humanities. Peter Suber, one of the fathers of the open access movement discussed these systemic barriers, in particular costly image rights moved him to state that 'open access will come last to art history.' However, I argue it is still imperative to make art scholarship open, but to overcome these challenges we need strong arguments for open access art scholarship, arguments that originate from the needs of our disciplines rather than those borrowed from the sciences. There are persuasive arguments for open access in art scholarship, arguments that mean we must endeavor to overcome the barriers to open access. In support of this I ask, what more could art scholarship achieve if it were open? How is traditional publishing hindering the evolution of art scholarship into a truly global discourse with relevance beyond academia? 


\section{Global Art Scholarship \& Open Access}

The expanding global art world and an increasingly global academic community are major concerns in the future of art scholarship. But the paywalls of traditional publishing have divided Western scholars from the rest of the world. University libraries are struggling to keep up with rapidly rising journal costs; even Harvard cannot afford all the subscriptions it would like. ${ }^{3}$ When even the expansive budgets of the wealthiest Western universities buckle under journal costs, then nonWestern libraries are simply priced out. Indeed university libraries across the developing world have been forced to cut journal subscriptions. ${ }^{4}$ While journals in the arts are less expensive, they are not freely available, and often are not a priority for limited journal funds. Although there are a few programs that give more affordable access to journal literature in the developing world, they are mostly limited both in scope (science and medicine) and in amount (a single article at a time). Increasingly, in many parts of the world, open access is the only access to art scholarship. This raises several serious problems for the status quo in art publishing.

This disparity in research access is happening at exactly the same time as art scholarship is striving to become more global: globalization has been called the most important question that currently faces art history. ${ }^{5}$ Art History focused on the Western tradition is rapidly diversifying and there has been much recent growth in writing on "non-Western" subjects. ${ }^{6}$ At the same time, the historically colonial nature of art scholarship, published in the West by Western scholars but about the non-Western world, is in the process of being transformed. Local and indigenous art histories are increasing around the globe. But a more inclusive scholarship cannot take place without discourse and dialogue, and it's a conversation that is choked off by conventional publishing models.

The divide in access means that scholarship on the developing world published in the West goes unread by the very cultures it is about. For example, 'Northern scholars writing on African countries do not need to worry about what their African colleagues think or say, especially if the latter are based on the continent, because they are unlikely to review their work. ${ }^{7}$ The best check on bias and inaccuracy in scholarship is its chance to be widely read and debated, and this is especially true of cross-cultural scholarship. Because the closed nature of traditional publishing cuts off transcultural discourses, 'Scholars need to question what constitutes an adequate circulation of theirs and others' work. ${ }^{8}$ There was a time when publishing in a well-regarded toll-access academic journal was thought to be sufficient to reach all those who would be interested in scholarly work. The time when such methods count as adequate dissemination is over. The idea that the only people interested in art scholarship are at a handful of major Western universities is simply not true, and for scholarship on non-western art, it is an attitude that is deeply problematic and patronizing.

Not only does toll-access publishing in the arts harm dissemination, it creates a vicious cycle further marginalizing international scholars. When scholars are cut off from the latest academic literature it becomes near impossible to keep up-to-date on theory. This makes it difficult for global art scholars to publish in Western journals as the peer-review process requires writers to be up-to-date on the most current Western scholarship. ${ }^{9}$ Instead, publication in these countries often occurs in local open access journals. Open access has been embraced around the world, both as a low cost method of disseminating scholarship as well as a means of to gain access to scholarship. ${ }^{10}$ Open access then is the key to supporting indigenous publishing and local research agendas that are also easily accessible to scholars in the west.

Despite the increasing amount of international scholarship published in open access journals, it often goes unread by Western academics. The traditional art indexes as a group have not kept up with global scholarship; mostly excluding journals published in other countries, and are heavily biased toward English and other European languages. ${ }^{11}$ These indexes have also not kept up with open access publications, at best managing to cover just $20 \%$ of open art history journals. ${ }^{12}$ Thus several factors are working together: non-Western scholars are priced out of access, this lack of access prevents publication, and Western scholars do not read global open access scholarship. Putting these conditions together we can see a clear break down in crosscultural academic communication.

\section{Art Scholarship \& the Public}

The paywalls of traditional publishing have created a divide between academia and the public, who have no way to access art scholarship. The point is often made that the public is not interested in academic analyses. However, art, theatre, music, film are all topics of great public interest. Museum shows 
and art fairs are routinely packed blockbusters. Contemporary art is fetching extreme prices and making front page news. Blogs and other online media analyze and review exhibits, galleries, and other art world developments. Thus, the idea that the scholarly analysis of these same topics that goes on in academic journals would have no general interest is hard to believe.

Often the point is made that academic writing is too esoteric to appeal to the general public. Lawrence McGill in a 2006 survey of art history editors found that, "Much recent scholarship comes across as 'narrow,' 'impenetrable,' 'unreadable,' and 'obscure.' Emerging scholars in the field are viewed as 'incapable of communicating with audiences broader than dissertation committees. ${ }^{13}$ However, this phenomenon seems to exist as a pernicious feedback loop. Art scholarship is not available to the general public, and so it is increasingly written and published for a small cadre of academics. Perhaps this cycle can be disrupted once scholars expect their work to see wide circulation and even witness its effect on public discourse. This wider readership would also have positive effects on public perception of the value of art scholarship.

Art scholars have a key role to play to introducing the public to new or rediscovered artists and periods, pointing out what to appreciate about them, sharing new insights and meanings. But the public is only exposed to information that is published in scholarly journals and locked behind paywalls after it has trickled down and made its way into museum wall plaques. A good example of this pattern is Caravaggio, an artist whose reputation and appreciation was resuscitated first in the scholarly literature, long before his fame reached a broader audience in the form of blockbuster museum exhibits. Art scholarship has the potential to illuminate anyone interested in art, and open access has the potential to facilitate that. It is a matter of equity: academic analysis of art should not just be available to those privileged with access to information but rather to "every young poor student [who should] be able to satisfy [their] learned curiosity just as a rich person does. ${ }^{, 14}$

Scholars could be natural leaders in the appreciation of art in society. But that role has largely been abdicated, as scholars have been content to talk only to each other. The limited availability of academic work may be giving the impression that art scholarship does not offer much of value to the public. The ramifications of this impression are seen in the endless articles about the value of the arts and humanities in contemporary society and the dismal funding environment for the arts. ${ }^{15} \mathrm{We}$ can see this attitude at even the most educated levels of society, for example, U.S. President Barack Obama recently joked about the usefulness of a major in art history. ${ }^{16}$ At a 2011 speaker series on this perception, many defended the arts and humanities as 'essential to understanding oneself and one's place in the world, the nature of existence, the very meaning of being human,' but as many of the participants admitted they were largely preaching to the choir. ${ }^{17}$ If we truly believe that art scholarship so enriches society, then we have an obligation to work towards a publishing model that can reach past the so-called 'choir' and become part of public discourse. It is vital not only for the public good, but for the good of the discipline.

\section{Librarians \& Open Access}

Librarians can help remove the paywalls that close off research. We can help open access to live up to its potential by making it known, used, and understood. Librarians hold a key role in creating an environment in which open access can flourish. We can become advocates, supporting and arguing for open scholarship. But we have to make the arguments in favor of open access resonate with art scholars. Our arguments cannot just be about the library and its budget, or arguments from the sciences that do not fit in an art context. We need to make the case that open access is important to the health and advancement of art scholarship.

Librarians work to connect researchers to information and ideas. We can extend this principle to bridging the divide between scholars and information published around the world open access. This work fits easily within the librarian's role, we already advertise resources and make them accessible; open access is no different. We can help art scholars find this information, and even more importantly, help them in turn make their research openly available world-wide. To get scholars to publish this way will take more than persuasive arguments; it also requires open access to be a practical alternative to traditional publishing. Librarians are already working to make open access easier for scholars, and must continue to innovate in this arena. Overall, our crucial work of facilitating scholars' finding and creating open access works can help to knit together a global community of art scholars. 


\section{Conclusion}

Open access is not just about the sciences or about journal prices. It is about the fundamental right to information. This was recognized even in 1948, when the Universal Declaration of Human Rights stated that people should have the 'freedom to ... seek, receive and impart information and ideas through any media and regardless of frontiers. ${ }^{18}$ As this quote suggests information often does not cross borders. Academic research can fail to reach global audiences through censorship but more often simply because of the expense of scholarly information. The price barriers of the traditional publishing system creates the situation where access to or participation in art scholarship is closed to all but privileged Western academics. This harms both the quality and appreciation of art scholarship. If we believe that art is not a luxury but a basic part of the human experience then neither should the scholarship that helps us grasp the deeper meanings of art be a luxury item.

\section{References}

1. Stephen Bosch and Kittie Henderson, 'Steps Down the Evolutionary Road I Periodicals Price Survey 2014,' Library fournal, April 11, 2014, http://lj.libraryjournal.com/2014/04/publishing/ steps-down-the-evolutionary-road-periodicalsprice-survey-2014/.

2. Peter Suber, 'Promoting Open Access in the Humanities,' 2004, http://www.earlham. edu/ peters/writing/apa.htm.

3. Ian Sample, 'Harvard University Says It Can't Afford Journal Publishers' Prices,' The Guardian, April 24, 2012, http://www.theguardian.com/ science/2012/apr/24/harvard-university-journalpublishers-prices.

4. John Willinsky, The Access Principle: The Case for Open Access to Research and Scholarship (Cambridge, MA: MIT Press, 2006).

5. James Elkins, 'Canon and Globalization in Art History, in Partisan Canons, ed. Anna Brzyski (Durham, NC: Duke University Press, 2007).

6. Elkins, "Canon and Globalization in Art History."

7. Paul Zeleza, 'Challenges in the Production and Globalization of African Knowledges,' 2008, http://www.zeleza.com/blogging/african-affairs/ challenges-productionand- globalization-africanknowledges-0. Date accessed: November, 2010. This website is no longer available.
8. Willinsky, The Access Principle, 109.

9. Willinsky, The Access Principle.

10. Shoshannah Holdom, 'E-Journal Proliferation in Emerging Economies: The Case of Latin America,' Literary and Linguistic Computing 20, no. 3 (September 1, 2005): 351-65.

11. Elkins, 'Canon and Globalization in Art History.'

12. Siân Evans, Hilary Thompson, and Alex Watkins, 'Discovering Open Access Art History: A Comparative Study of the Indexing of Open Access Art Journals,' The Serials Librarian 61, no. 2 (2011): 168-88.

13. Lawrence McGill, The State of Scholarly Publishing in the History of Art and Architecture, Connexions (Rice University, 2006), ttp://cnx. org/content/col10377/1.2.

14. Willinsky, The Access Principle, 6.

15. See for just a few examples: Geoffrey Galt Harpham, 'The Humanities' Value,' The Chronicle of Higher Education, March 20, 2009; Ellen Hazelkorn, 'Europe Looks for Better Ways to Measure the Value of the Arts and Humanities,' The Chronicle of Higher Education Blogs: WorldWise, January 10, 2013; Peter Conn, 'We Need to Acknowledge the Realities of Employment in the Humanities,' The Chronicle of Higher Education, April 4, 2010; Sandhya Kambhampati, 'Measuring Humanities Degrees Misses Much of Their Value,' The Chronicle of Higher Education Blogs: Data Points, October 20, 2014.

16. 'Obama Slights Art History Degrees,' Chronicle of Higher Education, January 30, 2014.

17. Jennifer Ruark, 'Defenders of the Humanities Look for New Ways to Explain Their Value,' The Chronicle of Higher Education, March 29, 2011, http://chronicle.com/article/Defendersof-the-Humanities/126930/.

18. 'The Universal Declaration of Human Rights,' Article 21, http://www.un.org/en/documents/ udhr/index.shtml.

Alexander Watkins

Art \& Architecture Librarian

University of Colorado Boulder

1720 Pleasant St.

Boulder 80309

Colorado

USA

Alexander.Watkins@colorado.edu 